\title{
Clinical Pharmacokinetics and Pharmacodynamics of Afatinib
}

\author{
Sven Wind ${ }^{1} \cdot$ David Schnell $^{1} \cdot$ Thomas Ebner $^{2} \cdot$ Matthias Freiwald $^{1}$. \\ Peter Stopfer ${ }^{1}$
}

Published online: 28 July 2016

(c) The Author(s) 2016. This article is published with open access at Springerlink.com

\begin{abstract}
Afatinib is an oral, irreversible ErbB family blocker that covalently binds to the kinase domains of epidermal growth factor receptor (EGFR), human EGFRs (HER) 2, and HER4, resulting in irreversible inhibition of tyrosine kinase autophosphorylation. Studies in healthy volunteers and patients with advanced solid tumours have shown that once-daily afatinib has time-independent pharmacokinetic characteristics. Maximum plasma concentrations of afatinib are reached approximately $2-5 \mathrm{~h}$ after oral administration and thereafter decline, at least bi-exponentially. Food reduces total exposure to afatinib. Over the clinical dose range of 20-50 mg, afatinib exposure increases slightly more than dose proportional. Afatinib metabolism is minimal, with unchanged drug predominantly excreted in the faeces and approximately $5 \%$ in urine. Apart from the parent drug afatinib, the major circulation species in human plasma are the covalently bound adducts to plasma protein. The effective elimination half-life is approximately $37 \mathrm{~h}$, consistent with an accumulation of drug exposure by 2.5- to 3.4-fold based on area under the plasma concentration-time curve (AUC) after multiple dosing. The pharmacokinetic profile of afatinib is consistent across a range of patient populations. Age, ethnicity, smoking status and hepatic
\end{abstract}

Electronic supplementary material The online version of this article (doi:10.1007/s40262-016-0440-1) contains supplementary material, which is available to authorized users.

Sven Wind

sven.wind@boehringer-ingelheim.com

1 Translational Medicine and Clinical Pharmacology, Boehringer Ingelheim Pharma GmbH \& Co KG, Birkendorfer Strasse 65, 88397 Biberach an der Riss, Germany

2 Drug metabolism and Pharmacokinetics, Boehringer Ingelheim Pharma GmbH \& Co KG, Birkendorfer Strasse 65, 88397 Biberach an der Riss, Germany function had no influence on afatinib pharmacokinetics, while females and patients with low body weight had increased exposure to afatinib. Renal function is correlated with afatinib exposure, but, as for sex and body weight, the effect size for patients with severe renal impairment (approximately $50 \%$ increase in AUC) is only mildly relative to the extent of unexplained interpatient variability in afatinib exposure. Afatinib has a low potential as a victim or perpetrator of drug-drug interactions, especially with cytochrome P450-modulating agents. However, concomitant treatment with potent inhibitors or inducers of the P-glycoprotein transporter can affect the pharmacokinetics of afatinib. At a dose of $50 \mathrm{mg}$, afatinib does not have proarrhythmic potential.

\section{Key Points}

Afatinib is an irreversible ErbB family blocker that is well absorbed, with maximum plasma concentration attained at $2-5 \mathrm{~h}$.

Afatinib demonstrates high apparent clearance after oral administration and is eliminated primarily as unchanged drug by faecal excretion.

Afatinib has a favourable and time-independent pharmacokinetic profile that is consistent across a range of patient populations.

Afatinib has a low potential for drug-drug interactions via cytochrome $\mathrm{P} 450$; coadministration of drugs that are potent inhibitors or inducers of P-glycoprotein should be undertaken with care.

Intrinsic factors such as age, ethnicity, and hepatic function do not affect the pharmacokinetics of afatinib.

Effects of sex, weight and renal function status are within the variability range of afatinib exposure. 


\section{Introduction}

In tumours arising from malignant epithelial cells, the ErbB family of proteins (Class I tyrosine kinase receptor pathway) is often dysregulated. The family is comprised of epidermal growth factor receptor (EGFR), human EGFRs 2, 3, and 4 (HER2, HER3 and HER4), and their cognate ligands [1]. This receptor pathway is implicated in the growth of malignant cells. The development of smallmolecule tyrosine kinase inhibitors (TKIs) that target EGFR has revolutionised the management of non-small cell lung cancer (NSCLC). The first-generation EGFRTKIs, erlotinib and gefitinib, compete reversibly with adenosine triphosphate (ATP) for binding to the intracellular catalytic domain of EGFR tyrosine kinase and thus inhibit EGFR autophosphorylation and downstream signalling [2]. Erlotinib and gefitinib are especially effective in tumours with activating EGFR mutations, evident in $10-15 \%$ of Caucasians and $40 \%$ of Asians with NSCLC [3]. In $90 \%$ of cases, these mutations are exon 19 deletions or exon 21 substitutions (L858R) [3]. However, these agents are susceptible to mutations that affect the binding affinity of ATP or the kinase inhibitor itself and, therefore, EGFR mutation-positive patients inevitably develop resistance to EGFR-TKIs after 9-12 months of treatment [4-8]. One important mechanism of acquired resistance is the T790M gatekeeper EGFR mutation in exon 20, which is found in approximately half of NSCLC cases $[9,10]$. This mutation increases the affinity of the mutant EGFR for its substrate, ATP, and thus reduces the efficacy of EGFRTKIs [10-13]. Less common mutations, such as amplification of the proto-oncogene MET, HER2 amplification, small cell transformation, and PIK3CA mutations, have been associated with the development of EGFR-TKI resistance in NSCLC $[9,10]$.

Newer, so called 'second-generation' EGFR-TKIs, including afatinib and dacomitinib, differ from erlotinib or gefitinib in that they form irreversible covalent bonds to the ATP-binding site of the EGFR receptor, and also target multiple ErbB family members, including HER2, which plays a key role in ErbB activation [14].

Afatinib is an oral, irreversible ErbB family blocker with activity in a wide range of tumour cell lines harbouring a hyperactivated ErbB signalling network [15, 16]. Afatinib has demonstrated clinical efficacy in phase III trials in patients with NSCLC and head and neck squamous cell cancer (HNSCC). In 2013, afatinib was approved for the first-line treatment of EGFR mutation-positive NSCLC $[17,18]$, based on the results of the LUX-Lung 3 and LUXLung 6 studies, which demonstrated a significant increase in progression-free survival (PFS) with afatinib compared with standard of care chemotherapy in EGFR-mutant patients with advanced NSCLC $[19,20]$. A pooled analysis of these two trials show a significant improvement in overall survival (OS) [31.7 vs. 20.7 months; hazard ratio $0.59 ; p=0.0001$ ] with afatinib in patients with exon 19 EGFR deletion compared with standard chemotherapy [21]. In patients with lung squamous cell cancer, afatinib has also demonstrated a significant increase in PFS and OS compared with erlotinib [22]. On 31 March 2016, the European Medicines Agency approved afatinib for the treatment of patients with advanced NSCLC of squamous cell histology progressing on or after platinum-based chemotherapy [23]. The recommended dose of afatinib is $40 \mathrm{mg}$ orally once daily; however, the dose can be increased to a maximum of $50 \mathrm{mg} /$ day, or decreased to a minimum of $20 \mathrm{mg} /$ day, depending on tolerability [17, 18]. In the event of potential drug-drug interaction, dose adjustment may be needed to avoid toxicity. Treatment is continued until disease progression or unacceptable toxicity.

This review discusses the pharmacokinetic and pharmacodynamic properties and drug-drug interaction profile of afatinib.

\section{Preclinical Pharmacology}

\subsection{Structure and Physicochemical Properties}

Afatinib $\left(\right.$ Giotrif $^{\circledR}$, Gilotrif $^{\circledR}$ ), also known as BIBW 2992 (Fig. 1), is an ATP-competitive 4-anilinoquinazoline derivative. Structural modelling studies demonstrate that it harbours a reactive acrylamide group that covalently binds to specific cysteine (Cys) residues in the kinase domains of EGFR $\left(\mathrm{Cys}^{773}\right)$, HER2 $\left(\mathrm{Cys}^{805}\right)$, and HER4 $\left(\mathrm{Cys}^{803}\right)$ receptors $[15,16,24]$.

Afatinib is administered as a film-coated tablet that contains afatinib as dimaleate salt. It is highly soluble throughout the physiological $\mathrm{pH}$ range of 1-7.5 [25], and

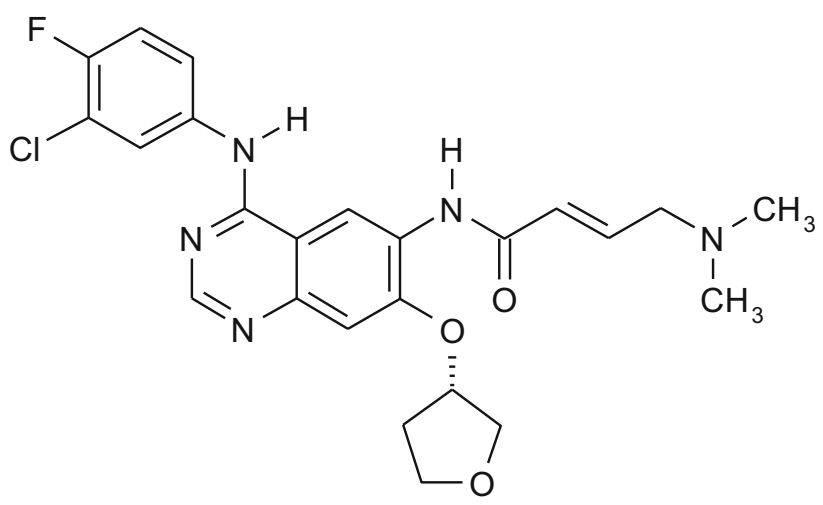

Fig. 1 Structural formula of afatinib (BIBW 2992): $N$-[4-[(3-chloro4-fluorophenyl)amino]-7-[[(3S)-tetrahydro-3-furanyl]oxy]-6-quinazolinyl]-4-(dimethylamino)-2-butenamide 
also shows high passive permeability through cell membranes, but efflux transport by intestinal P-glycoprotein (Pgp) can confound the permeability of afatinib as it is a P-gp substrate. Thus, no conclusive placement of afatinib in the Biopharmaceutics Classification System (BCS) is possible and it should be considered as either a BCS class 1 or 3 compound [26].

\subsection{Pharmacodynamic Properties}

\subsubsection{Mechanism of Action}

The covalent binding of afatinib to EGFR, HER2, and HER4 irreversibly inhibits the tyrosine kinase activity of these receptors, resulting in reduced auto- and transphosphorylation within the ErbB dimers and inhibition of important steps in the signal transduction of all ErbB receptor family members $[15,16]$. It also inhibits transphosphorylation of ErbB3 (HER3), thereby blocking signalling of all ErbB family members [15].

In cell-free in vitro kinase assays, afatinib showed nanomolar potency to inhibit wild-type EGFR, HER2 and ErbB4 (ErbB3 misses critical amino acid residues responsible for enzymatic activity, and thus has a much weaker tyrosine kinase activity) $[15,16,24]$. The potency of afatinib to inhibit the tyrosine kinase activity of wild-type EGFR (mean apparent half maximal effective concentration $\left[\mathrm{EC}_{50}\right]$ of $0.5 \mathrm{nM}$ ) was maintained on EGFR with the activating L858R mutation $\left(\mathrm{EC}_{50}\right.$ of $0.2 \mathrm{nM}$ ) [16] but reduced on the L858R/T790M double mutation of EGFR $\left(\mathrm{EC}_{50}\right.$ of $\left.9 \mathrm{nM}\right)$. Cellular activity demonstrated by inhibition of phosphorylation by afatinib was shown for EGFR, HER2, ErbB4 and of transphosphorylation for ErbB3 in a wide variety of cell lines, with potency in the low nanomolar range. Inhibition of autophosphorylation was demonstrated not only in cells expressing wild-type EGFR but also in those containing EGFR mutations, including L858R and L858R/T790M, at afatinib concentrations that can be achieved, at least transiently, in patients $[15,16]$. For a more thorough discussion about the preclinical efficacy profile of afatinib, the reader is referred to a recent comprehensive review by Modjtahedi et al. [24].

\subsection{In-Vitro Drug-Drug Interaction Victim and Perpetrator Properties}

Several in vitro metabolism, transport, and drug interaction studies were performed to quantitatively assess the drugdrug interaction potential of afatinib.

In vitro studies with human hepatocytes and human liver microsomes showed that afatinib had a low potential to inhibit or induce cytochrome P450 (CYP) isoenzymes (Boehringer Ingelheim, unpublished data) [26], including those that are most relevant for drug metabolism in humans (CYP1A1/2, CYP2B6, CYP2C8, CYP2C9, CYP2C19, CYP2D6 and CYP3A4) (Table 1) [27]. Further in vitro data indicated that drug-drug interactions with afatinib due to inhibition of UDP-glucuronosyltransferase 1A1 (UGT1A1) are considered unlikely [26].

In vitro bidirectional transport assays in human colon adenocarcinoma Caco-2 cell monolayers and human P-gp-expressing LLC-PK1 cells showed that afatinib is a substrate of the efflux transporter P-gp, and in vitro efflux transport was inhibited in the presence of cyclosporine A, verapamil and zosuquidar (all three compounds being potent P-gp inhibitors) [25, 26]. Further in vitro studies showed that afatinib is also a P-gp inhibitor, reducing the in vitro transport of the P-gp substrate digoxin $[25,26]$. In these studies, concentrations yielded an inhibition constant $\left(K_{i}\right)$ value of $3.4 \mu \mathrm{M}$ for afatinib. For comparison, the geometric mean (gMean) maximum plasma concentration $\left(C_{\max }\right)$ of afatinib $50 \mathrm{mg}$ at steady state was $0.158 \mu \mathrm{M}$, which is substantially below the afatinib concentration needed to inhibit P-gp.

Afatinib is also a substrate and inhibitor of the efflux transporter BCRP, with comparable in vitro inhibitory effects as for the known BCRP inhibitor fumitremorgin C $[25,26]$.

Studies using transfected HEK293 cell lines that express different drug transporters, including organic anion-transporting polypeptide (OATP), organic anion transporters (OAT) and organic cation transporters (OCT) showed no relevant in vitro transport of afatinib. Thus, active transport of afatinib by OATP, OAT and OCT drug transporters is not expected to be of in vivo relevance for the pharmacokinetics of afatinib in humans. At concentrations up to $100 \mu \mathrm{M}$, afatinib had a minor inhibitory effect on OATP1B1 and OATP1B3 $\left(\mathrm{IC}_{50}>70 \mu \mathrm{M}\right)$, and showed negligible in vitro inhibition of several other drug transporters (OAT1, OAT3, OCT2; $\left.\mathrm{IC}_{50}>100 \mu \mathrm{M}\right)$ (Table 1) [25]. Afatinib inhibited OCT1 and OCT3-mediated transport of the probe substrate $N$-methyl-4-phenyl pyridinium in a concentrationdependent manner, with $\mathrm{IC}_{50}$ values of 20.0 and $11.8 \mu \mathrm{M}$, respectively.

In summary, in the clinical setting, afatinib is unlikely to affect the pharmacokinetics of other drugs that are substrates of major drug metabolising CYPs or uptake transporters, such as OATP1B1, OATP1B3, OAT1, OAT3 or OCT2. Afatinib inhibits P-gp in vitro, but plasma concentrations of afatinib at therapeutic doses are considerably lower than concentrations expected to inhibit P-gp. 


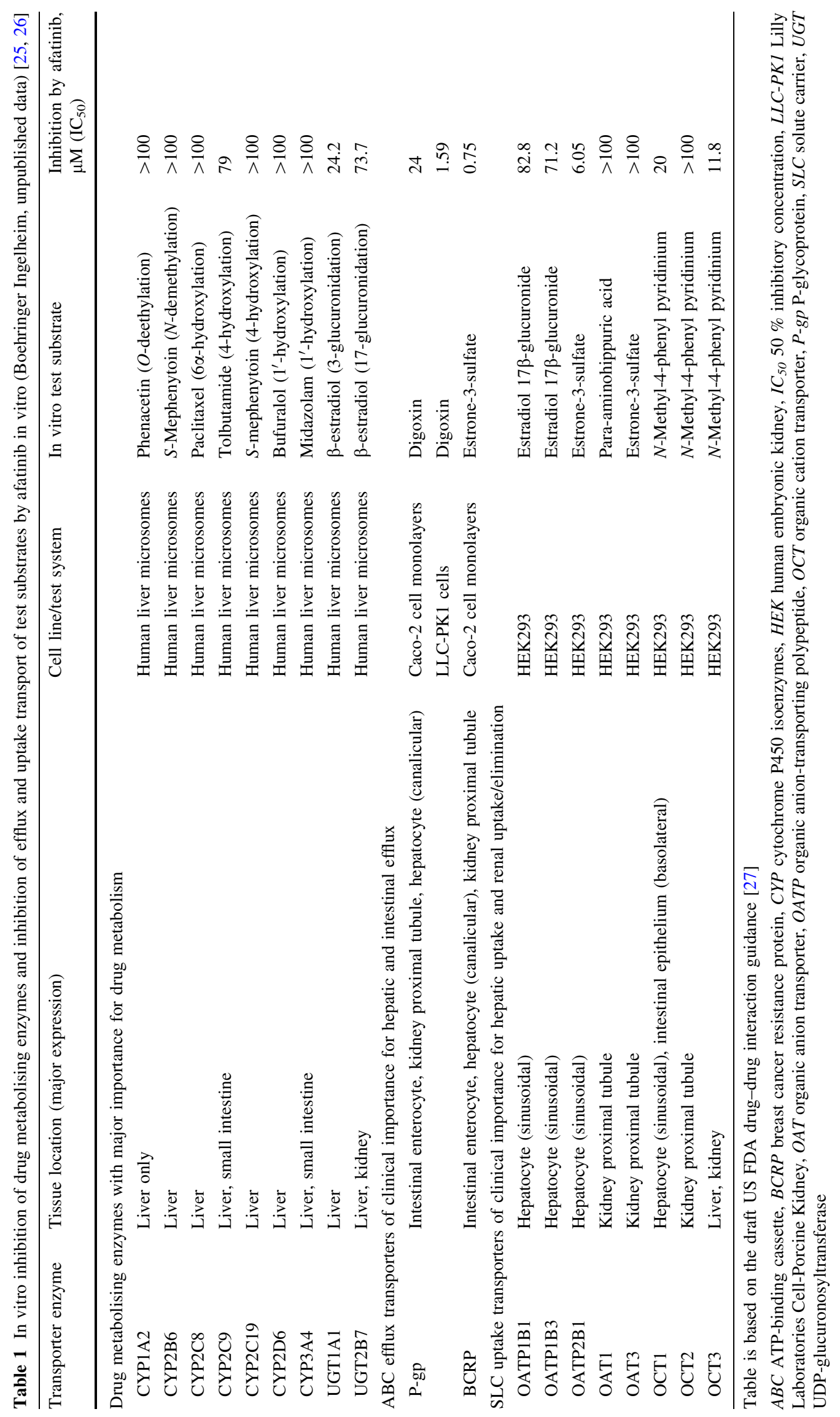




\subsection{Preclinical Pharmacokinetics}

The pharmacokinetics and drug metabolism of afatinib (dose as suspension/solution formulation of the dimaleate salt) were studied in several animal species (mice, rats, rabbits and Göttingen minipigs).

Absolute bioavailability of afatinib in rats and minipigs was variable, ranging from 11 to $45 \%$ (Boehringer Ingelheim, unpublished data) [25, 28]. Following administration of $\left[{ }^{14} \mathrm{C}\right]$-radiolabelled afatinib to rats and minipigs, radioactivity was widely distributed into most of the tissues, and declined slowly so that most tissues still had detectable levels at $312 \mathrm{~h}$. Pronounced body distribution was also shown by relatively large volumes of distribution of afatinib after intravenous dosing to animal species, which was 12.4 and $16.2 \mathrm{~L} / \mathrm{kg}$ in minipigs and rats, respectively.

Mean plasma protein binding of afatinib was $>92 \%$ in all animal species (rabbits, rats, minipigs and mice), over a concentration range of $0.05-0.5 \mu \mathrm{M}[25,28]$. In vitro, binding of afatinib dimaleate to isolated human serum albumin (45 g/L) was subordinate (79.6\%), and binding to human $\alpha 1$-acid glycoprotein (AGP) increased with the protein concentration from $11.6 \%(0.1 \mathrm{~g} / \mathrm{L}$ AGP $)$ to $90.6 \%$ (10 g/L AGP). The blood-to-plasma ratio of afatinib in vitro by incubation of $\left[{ }^{14} \mathrm{C}\right]$-radiolabelled afatinib in rats and minipigs was $>3$, indicating that afatinib was predominantly distributed into blood cells of these species.

In vivo metabolism was studied in several species (rats, mice, minipigs and rabbits) following oral and intravenous (rats only) administration of $\left[{ }^{14} \mathrm{C}\right]$-radiolabelled afatinib (Boehringer Ingelheim, unpublished data) [25, 28]. In all species, metabolism was minimal; excretion of unchanged parent compound accounted for $>50,>60,>72$, and $>87 \%$ in the rat, mouse, minipigs and rabbit, respectively. The total number of metabolites observed in all species at amounts $>1 \%$ of the administered dose was relatively small, with only minor differences in the metabolite pattern between the investigated species. In all animal species, the parent drug afatinib was the major circulating component in the plasma, with the next most predominant metabolites being the fraction of covalently bound afatinib. Across all investigated animal species, afatinib was primarily excreted in the faeces (85-94\% of the oral dose). Based on in vitro and in vivo toxicology studies, there was no evidence of genotoxicity with afatinib $[25,28]$.

\section{Clinical Pharmacokinetics}

The clinical pharmacokinetics of afatinib monotherapy were investigated in healthy subjects and patients with advanced solid tumours, including those with hepatic and renal impairment. To characterise the pharmacokinetics of afatinib in a large number of patients with advanced solid tumours, a meta-analysis of five phase I trials [29-32] and one phase II trial [33] in patients with advanced solid tumours $(n=221)$ who received afatinib $(10-100 \mathrm{mg}$ doses) was performed using non-compartmental analysis [34]. The key pharmacokinetic parameters following single and multiple doses of afatinib are presented in Tables 2 and 3. For comparison, Table 4 also gives the pharmacokinetic parameter estimates after multiple dosing of $40 \mathrm{mg}$ to a typical NSCLC patient based on a population
Table 2 Summary of singledose pharmacokinetics of afatinib after once-daily oral doses in cancer patients enrolled in four phase I trials [29-32] and one phase II trial [33]. Results are based on a metaanalysis of data from these five trials [34]

\begin{tabular}{lllll}
\hline Parameter and unit & \multicolumn{4}{l}{ Afatinib dose } \\
\cline { 2 - 5 } & $20 \mathrm{mg}(N=13)$ & $30 \mathrm{mg}(N=10)$ & $40 \mathrm{mg}(N=30)$ & $50 \mathrm{mg}(N=73)$ \\
\hline $\mathrm{AUC}_{24}[\mathrm{ng} \cdot \mathrm{h} / \mathrm{mL}]$ & $119(56.6)^{\mathrm{a}}$ & $189(95.9)$ & $324(68.9)$ & $459(68.0)^{\mathrm{b}}$ \\
$C_{\max }[\mathrm{ng} / \mathrm{mL}]$ & $11.6(85.1)$ & $16.3(139)$ & $25.2(73.3)$ & $40.8(76.6)$ \\
$t_{\max }[\mathrm{h}]$ & $3.00(0.50-24.0)$ & $2.00(0.57-6.92)$ & $3.98(0.58-9.10)$ & $3.13(0.90-9.05)$ \\
$t_{1 / 2}[\mathrm{~h}]$ & $22.3(80.3)^{\mathrm{c}}$ & $21.3(82.1)$ & $26.9(61.1)$ & $21.9(54.8)^{\mathrm{d}, \mathrm{e}}$ \\
$\mathrm{CL} / \mathrm{F}[\mathrm{mL} / \mathrm{min}]$ & $1430(64.7)^{\mathrm{c}}$ & $1370(72.9)$ & $952(86.2)$ & $1090(94.0)^{\mathrm{d}, \mathrm{e}}$ \\
$\mathrm{V}_{\mathrm{z}} / \mathrm{F}[\mathrm{L}]$ & $2770(61.8)^{\mathrm{c}}$ & $2520(109)$ & $2220(71.4)$ & $2080(123)^{\mathrm{d}, \mathrm{e}}$ \\
\hline
\end{tabular}

Data are expressed as geometric mean $[g C V(\%)]$ or median (range)

$A U C_{24}$ area under the drug plasma concentration-time curve over the time interval from zero to $24 \mathrm{~h}, C L / F$ clearance of drug from plasma after oral administration, $C_{\max }$ maximum drug concentration in plasma, $g C V(\%)$ geometric coefficient of variation $(\%), t_{1 / 2}$ terminal elimination half-life, $t_{\max }$ time to reach $C_{\max }, V_{z} / F$ (apparent) volume of distribution

${ }^{\text {a }} n=12$

b $n=69$

${ }^{\mathrm{c}} n=11$

d $n=13$

e No $t_{1 / 2}$-dependent parameters were calculated in one trial [33] 
Table 3 Summary of steadystate pharmacokinetics of afatinib after multiple oncedaily oral doses in cancer patients enrolled in four phase I trials [29-32] and one phase II trial [33]. Results are based on a meta-analysis of data from these five trials [34]

\begin{tabular}{lllll}
\hline Parameter and unit & \multicolumn{4}{l}{ Afatinib dose } \\
\cline { 2 - 5 } & $20 \mathrm{mg}(N=15)$ & $30 \mathrm{mg}(N=8)$ & $40 \mathrm{mg}(N=27)$ & $50 \mathrm{mg}(N=51)$ \\
\hline $\mathrm{AUC}_{\tau, \mathrm{ss}}[\mathrm{ng} \cdot \mathrm{h} / \mathrm{mL}]$ & $380(77.2)$ & $660(92.4)$ & $631(85.9)^{\mathrm{a}}$ & $1130(59.7)$ \\
$C_{\text {max }, \mathrm{ss}}[\mathrm{ng} / \mathrm{mL}]$ & $24.5(88.5)$ & $46.5(120)$ & $38.0(105)$ & $77.0(63.6)$ \\
$t_{\mathrm{max}, \mathrm{ss}}[\mathrm{h}]$ & $4.98(0.50-9.08)$ & $2.01(0.52-4.00)$ & $3.00(0.47-23.8)$ & $3.82(1.00-7.05)$ \\
$t_{1 / 2, \mathrm{ss}}[\mathrm{h}]$ & $47.1(51.6)$ & $33.4(56.8)^{\mathrm{b}}$ & $36.3(57.1)^{\mathrm{c}}$ & $22.3(25.4)^{\mathrm{d}}$ \\
$\mathrm{CL} / \mathrm{F}_{\mathrm{ss}}[\mathrm{mL} / \mathrm{min}]$ & $877(77.2)$ & $758(92.4)$ & $1070(87.9)^{\mathrm{e}}$ & $1390(47.3)^{\mathrm{d}}$ \\
$V_{z} / F_{\mathrm{ss}}[\mathrm{L}]$ & $3570(107)$ & $2000(67.8)^{\mathrm{b}}$ & $2870(101)^{\mathrm{c}}$ & $2690(47.8)^{\mathrm{d}}$ \\
$\mathrm{R}_{\mathrm{A}, \mathrm{AUC}}$ & $3.14(27.6)^{\mathrm{f}}$ & $3.40(83.1)$ & $2.53(48.0)^{\mathrm{g}}$ & $2.61(59.1)^{\mathrm{h}}$ \\
$\mathrm{R}_{\mathrm{A}, \mathrm{Cmax}}$ & $2.23(26.5)^{\mathrm{i}}$ & $2.67(98.8)$ & $2.08(57.7)^{\mathrm{g}}$ & $2.00(69.2)$ \\
\hline
\end{tabular}

Data are expressed as geometric mean $[g C V(\%)]$ or median (range)

$A U C_{\tau, \mathrm{ss}}$ area under the drug plasma concentration-time curve at steady state over a uniform dosing interval $\tau, C L / F_{\mathrm{ss}}$ clearance of drug from plasma after oral administration at steady state, $C_{\max , \text { ss }}$ maximum drug concentration in plasma at steady state, $g C V(\%)$ geometric coefficient of variation $(\%), R_{A, A U C}$ accumulation ratio based on $A U C, R_{A, C \max }$ accumulation ratio based on $C_{\max }$, ss steady state, $t_{1 / 2, \mathrm{ss}}$ terminal elimination half-life at steady state, $t_{\max , \mathrm{ss}}$ time to reach $C_{\max , \mathrm{ss}}, V_{z} / F_{\mathrm{ss}}$ (apparent) volume of distribution at steady state

${ }^{\mathrm{a}} n=26$

b $n=7$

c $n=23$

d $n=7$ (no $t_{1 / 2}$-dependent parameters were calculated in one trial [33])

e $n=25$

f $n=11$

g $n=9$

${ }^{\text {h }} n=49$

${ }^{\mathrm{i}} n=12$
Table 4 PopPK model-derived afatinib secondary steady-state pharmacokinetic parameters after multiple once-daily dosing of afatinib $40 \mathrm{mg}$ to a typical patient ${ }^{\mathrm{a}}$ [35]

\begin{tabular}{ll}
\hline Parameter & Population mean estimate \\
\hline $\mathrm{AUC}_{\tau, \mathrm{ss}}[\mathrm{ng} \cdot \mathrm{h} / \mathrm{mL}]$ & 908 \\
$C_{\mathrm{max}, \mathrm{ss}}[\mathrm{ng} / \mathrm{mL}]$ & 49.2 \\
$t_{\text {max,ss }}[\mathrm{h}]$ & 4.25 \\
$t_{1 / 2, \mathrm{ss}}[\mathrm{h}]$ & 45.0 \\
$\mathrm{CL} / F_{\mathrm{ss}}[\mathrm{mL} / \mathrm{min}]$ & 734 \\
$V / F_{\mathrm{ss}}[\mathrm{L}]$ & 2370 \\
$V_{z} / F_{\mathrm{ss}}[\mathrm{L}]$ & 2860
\end{tabular}

$A U C_{\tau, \mathrm{ss}}$ area under the drug plasma concentration-time curve at steady-state over a uniform dosing interval $\tau, C L / F_{\text {ss }}$ clearance of drug from plasma at steady state after oral administration, $C_{\text {max,ss }}$ maximum drug concentration in plasma at steady state, ECOG Eastern Cooperative Oncology Group, $L D H$ lactate dehydrogenase, $N S C L C$ non-small cell lung cancer, PopPK population pharmacokinetic, ss steady state, $t_{1 / 2, s s}$ terminal elimination half-life at steady state, $t_{\max , s s}$ time to reach $C_{\max , s s}, V / F_{s s}$ apparent volume of distribution at steady state, $V_{z} / F_{s s}$ apparent volume of distribution during the terminal phase at steady state

${ }^{a}$ Median and mode of baseline characteristics within the analysed population, i.e. female with NSCLC, weighing $62 \mathrm{~kg}$, ECOG score of 1, creatinine clearance $79 \mathrm{~mL} / \mathrm{min}, \mathrm{LDH}$ level $241 \mathrm{U} / \mathrm{L}$, alkaline phosphatase level $106 \mathrm{U} / \mathrm{L}$, and total protein level $72 \mathrm{~g} / \mathrm{L}$, who received doses in a fasting state pharmacokinetic (PopPK) model using data from 927 patients with advanced solid tumours included in seven phase II/III studies [35].

\subsection{Absorption and Distribution}

Following oral administration, afatinib attains $C_{\max }$ values within approximately 2-5 h (range $0.5-24 \mathrm{~h}$ ) (Tables 2,3 ) [34], delayed slightly by food intake ( $C_{\max }$ occurs at 3-8 h) [30]. gMean plasma concentration-time profiles of afatinib for dose levels $20-50 \mathrm{mg}$ after single and multiple dosing are shown in Fig. 2. The shape of the gMean plasma concentration-time profiles after single and multiple doses are generally similar across all doses and, after reaching $C_{\max }$, decline at least bi-exponentially.

Increases in $C_{\max }$ and area under the plasma concentration-time curve (AUC) in the dose range of $20-50 \mathrm{mg}$ are slightly more than dose proportional (Tables 2, 3) [34], potentially due to changes in the bioavailability of afatinib as a result of saturation of efflux transporters in the gut [34]. Steady-state is achieved within 8 days of once-daily dosing, with overall accumulation ratios of 2.0-2.7 for $C_{\max }$ and 2.5-3.4 for AUC, and no evidence of fluctuation in subsequent treatment cycles [34] (electronic supplementary Fig. 1). 
Fig. 2 Geometric mean afatinib plasma concentration-time profiles after single doses and at steady-state following oral administration of afatinib (20-50 mg) once daily to cancer patients (linear scale). $n=$ maximum number of patients contributing to the geometric mean of each time point for afatinib single doses and at steady-state. Reproduced from Wind et al. [34], with permission of Springer

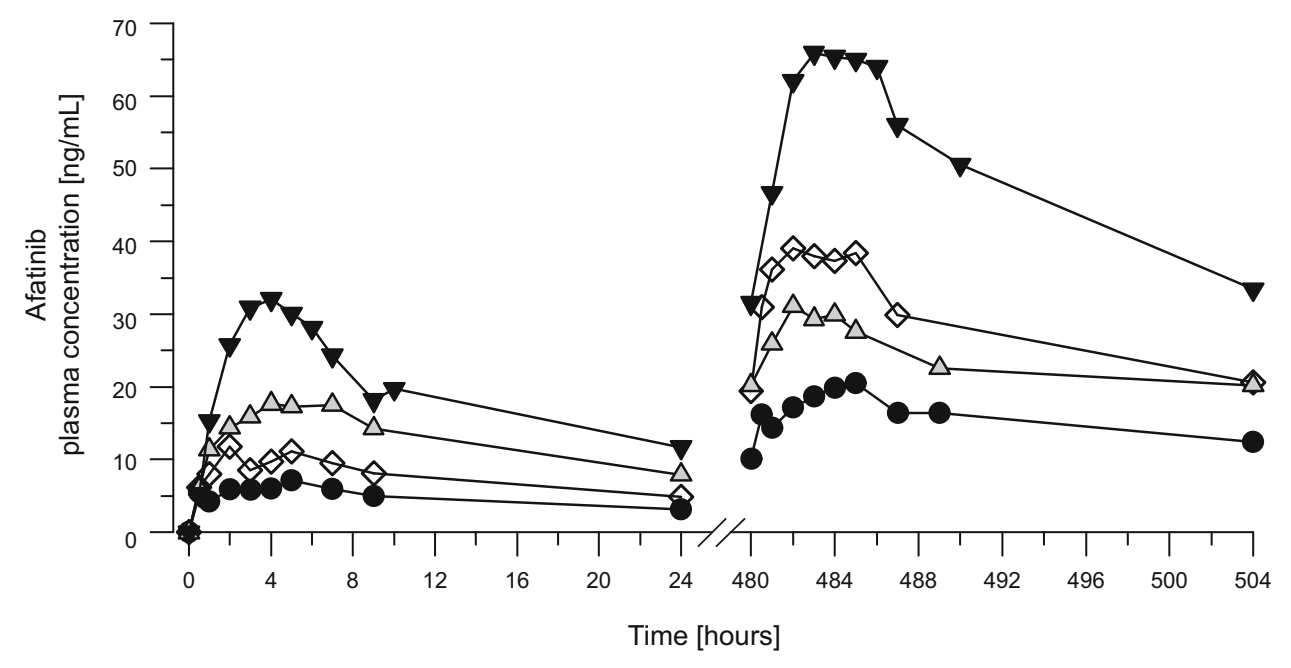

$\triangle \_40 \mathrm{mg}(\mathrm{n}=48 / 29)$

$\longrightarrow-50 \mathrm{mg}(\mathrm{n}=73 / 52)$
In line with this, a two-compartment disposition model with first-order absorption, linear elimination and dosedependent bioavailability was used when performing compartmental analyses [35].

The absolute bioavailability of afatinib in humans has not been studied. Relative bioavailability was $92 \%(90 \%$ confidence interval [CI] 76-112\%) based on the AUC from time zero to infinity $\left(\mathrm{AUC}_{\infty}\right)$, and $85 \%(90 \% \mathrm{CI}$ $69-106 \%$ ) based on $C_{\max }$ after a single dose of a $20 \mathrm{mg}$ tablet compared with an oral solution [36]. After a high-fat, high-caloric meal [37], afatinib exposure is reduced, with $C_{\max }$ and $\mathrm{AUC}_{\infty}$ reduced by approximately $50 \%$ and $39 \%$, respectively. Thus, afatinib should be administered at least $1 \mathrm{~h}$ before or 2-3 $\mathrm{h}$ after ingestion of food [17, 18].

Afatinib is approximately $95 \%$ plasma protein bound $[38,39]$. In the previously described meta-analysis, afatinib (10-100 mg doses) showed a high apparent volume of distribution during the terminal phase $\left(V_{z} / F\right)$ after single doses and at steady state (gMean values were 1940 and $2770 \mathrm{~L}$, respectively), indicative of high tissue distribution [34]. In line with this, $V_{z} / F$ was $2860 \mathrm{~L}$ for a typical patient receiving a $40 \mathrm{mg}$ dose, based on the PopPK analysis (Table 4) [35]. However, the values of $V_{z} / F$ should be treated with caution as the absolute bioavailability $(F)$ of afatinib is unknown. The final PopPK model adequately described the pharmacokinetics of afatinib in different cancer patient populations.

\subsection{Metabolism and Elimination}

The disposition and metabolism of afatinib were investigated in a dedicated absorption, distribution, metabolism, and elimination (ADME) study in eight male subjects who received a single oral dose of $\left[{ }^{14} \mathrm{C}\right.$-]radiolabelled afatinib solution [40]. Following an oral dose of $15 \mathrm{mg}\left[{ }^{14} \mathrm{C}\right]$-radiolabelled afatinib dimaleate, most of the dose was recovered in the faeces ( $85.4 \%$ within $312 \mathrm{~h}$ after dosing), with negligible clearance in the urine $(4.29 \%$ within $216 \mathrm{~h}$ after dosing). The renal excretion of afatinib itself was also low, which suggests primarily biliary secretion of unchanged drug. The combined faecal and urinary recovery accounted for $89.5 \%$ of the administered $\left[{ }^{14} \mathrm{C}\right]$-radiolabelled dose, indicative of an essentially complete mass balance. Most of the recovery occurred within $72 \mathrm{~h}$ of dosing.

Metabolite profiling showed that afatinib was metabolised to a minor extent [40] and the parent compound (afatinib) was the major drug-related component in plasma, urine and faeces. The major circulating form of afatinib in human plasma were adducts of afatinib covalently bound to plasma proteins (e.g. albumin) via a chemical reaction mechanism of Michael addition that does not involve enzymatic catalysis. No metabolites formed by CYP enzymes were detected in excreta. Oxidative metabolism mediated via CYPs was of negligible importance for the metabolism and elimination of afatinib, suggesting that the risk of interaction between afatinib and other therapies metabolised by CYP enzymes (i.e. CYP substrates, CYP inhibitors and CYP inducers), is minimal.

Overall drug clearance (CL/F) was comparable after single doses and at steady state (gMean 1050 and $898 \mathrm{~mL} / \mathrm{min}$, respectively). The gMean terminal half-life was $21 \mathrm{~h}$ (range $21-27 \mathrm{~h}$ ) after single doses and $37 \mathrm{~h}$ (predominantly ranging from 22 to $47 \mathrm{~h}$ ) at steady state 


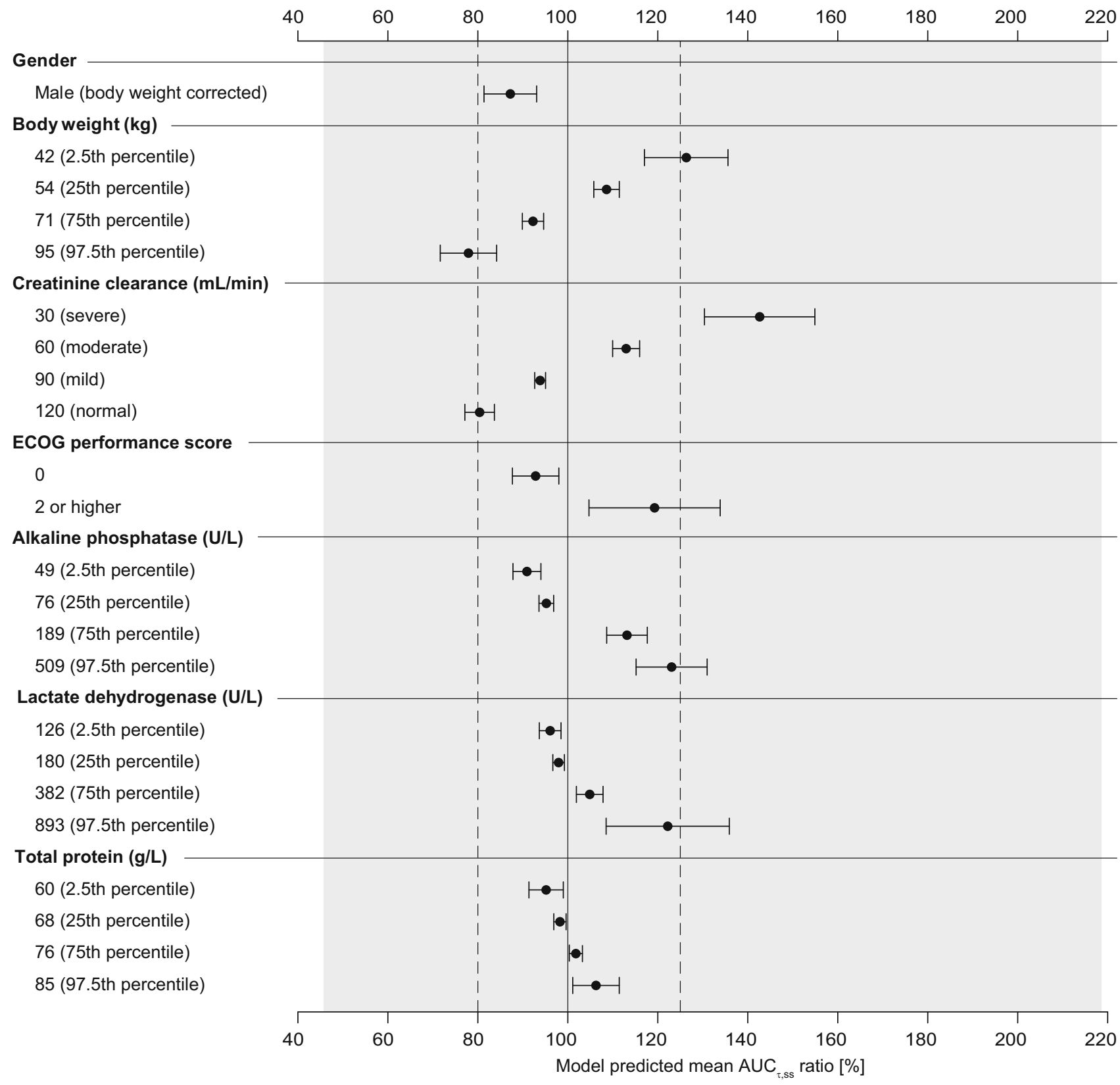

- Point estimate from final population pharmacokinetic model and 95\% confidence interval

Reference patient $=$ Female, Body weight $62 \mathrm{~kg}$, Creatinine clearance $79 \mathrm{~mL} / \mathrm{min}$, ECOG performance score 1 , Alkaline phosphatase $106 \mathrm{U} / \mathrm{L}$, Lactate dehydrogenase $241 \mathrm{U} / \mathrm{L}$, Total protein $72 \mathrm{~g} / \mathrm{L}$, Cancer type NSCLC

Bioequivalence limits $(80-125 \%)$

$90 \%$ prediction interval for inter-patient variability

Fig. 3 Ratios (point estimates and $95 \%$ confidence interval based on bootstrap analysis) of afatinib population mean exposure at steady state $\left(\mathrm{AUC}_{\tau}\right)$ predicted by the population pharmacokinetic model for different scenarios compared with a typical patient. *Typical patient was female with NSCLC, body weight $62 \mathrm{~kg}$, creatinine clearance $79 \mathrm{~mL} / \mathrm{min}$, ECOG score of 1, alkaline phosphatase $106 \mathrm{U} / \mathrm{L}$, lactate dehydrogenase $241 \mathrm{U} / \mathrm{L}$, total protein $72 \mathrm{~g} / \mathrm{L}$, receiving afatinib $40 \mathrm{mg}$ once daily. The solid vertical line indicates the population mean for the typical patient, and the shaded area is the $90 \%$ prediction interval for interpatient variability. The vertical dotted lines indicate the bioequivalence limits (80-125\%). The 2.5th, 25th, 75 th and 97.5 th percentiles of the baseline values observed in the analysed population are shown for body weight, alkaline phosphatase, lactate dehydrogenase and total protein. Data for the creatinine clearance subgroups are based on the US FDA classification of renal function [41]. $A U C_{\tau}$ area under the drug plasma concentration-time curve over a uniform dosing interval $\tau, E C O G$ Eastern Cooperative Oncology Group, NSCLC non-small cell lung cancer. Reproduced from Freiwald et al. [35], with permission of Springer 
(10-100 mg doses) in the phase I meta-analysis [34]. A half-life of approximately $37 \mathrm{~h}$ can be also calculated based on the accumulation ratio, and can thus be considered as the effective half-life of afatinib. However, the real terminal half-life of afatinib seems to be significantly longer, as suggested by recent studies with more sensitive bioanalytical assays and longer pharmacokinetic sampling periods after dosing. A terminal half-life of 70-80 h was determined after single-dose administration and subsequent pharmacokinetic sampling up to $312 \mathrm{~h}$ [38, 39], and up to approximately $340 \mathrm{~h}$ after multiple dosing in patients who stopped afatinib therapy after at least 6 months of treatment and had pharmacokinetic sampling up to 6 weeks after the last dose (Boehringer Ingelheim, unpublished data). This phenomenon may be explained by afatinib's feature to form covalently bound adducts with proteins via Michael addition, which is a chemical equilibrium. These covalent protein adducts can decompose and slowly release afatinib, leading to the prolonged elimination phase. However, this prolonged terminal halflife after long-term treatment does not contribute to the accumulation of the drug, and resulting afatinib plasma levels are far below the exposure known to exert pharmacological efficacy or adverse effects.

\subsection{Variability in Exposure}

Substantial variability was observed in afatinib exposure in the clinical trials; for example, geometric coefficient of variation $(\mathrm{gCV})$ values for AUC across the dose range $20-50 \mathrm{mg}$ ranged from 60 to $92 \%$ in the phase I metaanalysis [26].

Interindividual variability is still moderate to high, even after accounting for known effects of intrinsic and extrinsic factors as illustrated in Fig. 3 by the $90 \%$ prediction interval of afatinib exposure for an individual NSCLC patient based on a recent PopPK analysis using data from
927 patients with advanced solid tumours included in seven phase II/III studies [35].

In the target population of NSCLC patients from the LUX-Lung 3 trial, afatinib plasma levels also showed high interpatient variability (gCV from 67 to $85 \%$ with a $40 \mathrm{mg}$ dose) [19]. However, the applied dose reduction schedule in LUX-Lung 3 was effective in reducing excessive plasma concentrations, thus reducing the interpatient variability in exposure (gCV reduced from $85 \%$ [day 1 of cycle two] to $67 \%$ [day 1 of cycle three]) and thereby providing similar plasma levels for patients across the dose groups [19] (see Sect. 7.2).

In the phase I meta-analysis, intraindividual variability for afatinib trough plasma concentrations over the treatment cycles was moderate, with gCVs ranging from 31.0 to $35.7 \%$ for the 20, 30, 40 and $50 \mathrm{mg}$ dose groups [34].

\section{Pharmacokinetics in Special Populations}

\subsection{Pharmacokinetics in Subjects with Renal Impairment}

In a single-dose study of afatinib $40 \mathrm{mg}$ in subjects with moderate $(n=8)$ or severe $(n=8)$ renal impairment (estimated glomerular filtration rate [eGFR] 30-59 and 15-29 $\mathrm{mL} / \mathrm{min}$, respectively) and healthy matched controls ( $n=14$ ) [39], the plasma concentration-time profile of afatinib was similar in both groups. An increase in afatinib exposure and a decrease in renal clearance with decreased renal function was observed, as assessed by eGFR, although overall afatinib terminal half-lives were similar in subjects with renal impairment. The extent of exposure, as indicated by area under the drug plasma concentrationtime curve from time zero to the time of the last quantifiable data point $\left(\mathrm{AUC}_{\text {last }}\right)$ and $C_{\max }$, was generally similar between the matched treatment groups (Table 5), with the

Table 5 Relationship between degree of renal or hepatic impairment and afatinib pharmacokinetic parameters (adapted from Schnell et al. [38] and Wiebe et al. [39])

\begin{tabular}{|c|c|c|c|c|}
\hline \multirow[t]{2}{*}{ Comparison of grades of renal/hepatic impairment } & \multicolumn{2}{|l|}{ Renal impairment study } & \multicolumn{2}{|c|}{ Hepatic impairment study } \\
\hline & $\mathrm{AUC}_{\text {last }}(\mathrm{ng} \cdot \mathrm{h} / \mathrm{mL})$ & $C_{\max }(\mathrm{ng} / \mathrm{mL})$ & $\mathrm{AUC}_{\infty}(\mathrm{ng} \cdot \mathrm{h} / \mathrm{mL})$ & $C_{\max }(\mathrm{ng} / \mathrm{mL})$ \\
\hline Mild vs. healthy matched controls & NA & NA & $92.6(68.0-126.3)^{\mathrm{a}}$ & $109.5(82.7-144.9)^{\mathrm{a}}$ \\
\hline Moderate vs. healthy matched controls & $122.2(95.7-156.0)^{\mathrm{a}}$ & $101.2(72.9-140.3)^{\mathrm{a}}$ & $94.9(72.3-124.5)^{\mathrm{a}}$ & $126.9(86.0-187.2)^{\mathrm{a}}$ \\
\hline Severe vs. healthy matched controls & $150.0(105.3-213.7)^{\mathrm{a}, \mathrm{b}}$ & $121.7(90.8-163.2)$ & NA & NA \\
\hline
\end{tabular}

Data are expressed as adjusted geometric mean ratios $(90 \% \mathrm{CI})$

$A U C_{\text {last }}$ area under the drug plasma concentration-time curve from time zero to the time of the last quantifiable data point, $A U C_{\infty}$ area under the drug plasma concentration-time curve from time zero to infinity, $C I$ confidence interval, $C_{\max }$ maximum concentration, $N A$ not applicable

${ }^{\text {a }} n=8$ per group in each comparison shown

${ }^{\mathrm{b}} p=0.06$ (two-sided $p<0.1$ indicates formal significance) 
exception of the gMean ratio of $\mathrm{AUC}_{\text {last }}$ for subjects with severe renal impairment, which showed a trend towards a higher value compared with matched healthy subjects. Renal impairment had no effect on plasma protein binding of afatinib. The relatively minor influence on the pharmacokinetics of afatinib is in line with the results from a recent PopPK analysis based on phase II and III data testing creatinine clearance $\left(\mathrm{CL}_{\mathrm{CR}}\right)$ as a covariate, and is within the known interpatient variability of afatinib exposure (Fig. 3) [35]. Based on the low urinary excretion of afatinib-related radioactivity $(<5 \%)$ found in the ADME study [40], the renal impairment study [39] and the PopPK analysis [35], it may be hypothesized that non-renal elimination pathways of afatinib are impacted by renal function, such as a decrease in expression and/or activity of intestinal P-gp [42, 43].

\subsection{Pharmacokinetics in Subjects with Hepatic Impairment}

In a single-dose study of afatinib $50 \mathrm{mg}$ in subjects with mild $(n=8)$ or moderate $(n=8)$ hepatic impairment (Child-Pugh A and B grades, respectively) and matched healthy controls $(n=16$ ) [38], plasma concentrations were generally similar as the mean ratios for $C_{\max }$ and $\mathrm{AUC}_{\infty}$ varied between 92.6 and $126.9 \%$ (Table 5). No correlation between degree of hepatic impairment and pharmacokinetics was observed.

Hepatic impairment had no effect on plasma protein binding of afatinib. Since metabolism of afatinib is negligible [40], there is no effect on biliary excretion of predominantly unchanged afatinib, consistent with findings from the PopPK model, which showed that the presence of liver dysfunction associated with liver metastases had no significant impact on the exposure (AUC) of afatinib [35].

Overall, these results imply that hepatic function does not influence the exposure to afatinib; however, it should be noted that data in patients with severe hepatic impairment (Child-Pugh C) are sparse. Therefore, the EU prescribing guidelines state that treatment with afatinib is not recommended in patients with severe hepatic impairment [18], while the US prescribing information states that patients with severe hepatic impairment should be closely monitored and the afatinib dose adjusted if not tolerated [17].

\section{Drug-Drug Interactions}

Afatinib is not metabolised to an appreciable extent and does not relevantly inhibit or induce CYP enzymes. Since it is highly soluble throughout the physiological $\mathrm{pH}$ range of 1-7.5 [25], any drug-drug interactions with acid- reducing drugs such as $\mathrm{H}_{2}$-receptor antagonists, proton pump inhibitors and antacids are not expected.

In vitro data suggest that afatinib is a BCRP substrate and inhibitor. Because no specific in vivo BCRP modulators or substrates are available, which could be administered to subjects, no dedicated clinical study was performed to address the clinical drug-drug interaction potential of afatinib with regard to substrates of this efflux transporter.

As mentioned, afatinib inhibits P-gp in vitro, but plasma concentrations of afatinib at therapeutic doses are considerably lower than concentrations expected to inhibit P-gp. In line with this, concomitant administration of afatinib with sirolimus, a P-gp substrate, did not result in a clinically relevant change in exposure of either drug [44], suggesting that afatinib has low or negligible interaction potential with other P-gp substrates [18]. This also suggests that there are no drug-drug interactions likely between afatinib and P-gp substrates at the absorption site in the gut, where potentially higher local afatinib concentrations could occur compared with systemic plasma levels.

Since afatinib is a substrate of P-gp in vitro, coadministration of potent inhibitors and inducers of this efflux transporter can potentially modify its exposure (AUC and $C_{\text {max }}$ ). Several phase I drug-drug interaction studies were performed to investigate the interaction potential with potent P-gp modulators [45].

\subsection{Ritonavir}

Two drug-drug interaction studies in healthy subjects evaluated the effect on afatinib exposure of the potent P-gp and BCRP inhibitor ritonavir (200 $\mathrm{mg}$ twice daily) administered $1 \mathrm{~h}$ before, concomitantly, or $6 \mathrm{~h}$ after afatinib [45]. Coadministration of ritonavir did not relevantly change the exposure to afatinib $40 \mathrm{mg}$ when taken concomitantly or $6 \mathrm{~h}$ after afatinib, but increased exposure to afatinib $20 \mathrm{mg}$ by $48 \%\left(\mathrm{AUC}_{\infty}\right)$ and $39 \%\left(C_{\max }\right)$ when administered $1 \mathrm{~h}$ before afatinib (Fig. 4). The lack of interaction with the afatinib $40 \mathrm{mg}$ dose can be explained by two potential mechanisms; on one hand, P-gp-mediated transport might be saturated and thus be of minor relevance for exposure at the $40 \mathrm{mg}$ dose level, which would be in line with the slightly more than dose proportional increase in exposure in the therapeutic dose range. On the other hand, the concomitant and $6 \mathrm{~h}$ staggered administration of ritonavir led to a time delay in P-gp inhibition that did not relevantly affect afatinib exposure. However, as data confirm that potent P-gp inhibitors may increase exposure to afatinib, caution should be exercised when afatinib needs to be combined with such comedications. It is recommended that P-gp inhibitors should be administered in a staggered dosing regimen, i.e. with as large as possible interval from the afatinib dose, preferably $6 \mathrm{~h}$ (if administered twice 
Fig. 4 Effect of ritonavir and rifampicin on afatinib exposure. Broken vertical lines illustrate the no-effect boundaries $(0.8-1.25)$ used in the assessment. AUC area under the plasma concentration-time curve, $C I$ confidence interval, $C_{\max }$ maximum plasma concentration. Reproduced from Wind et al. [45], with permission of Springer

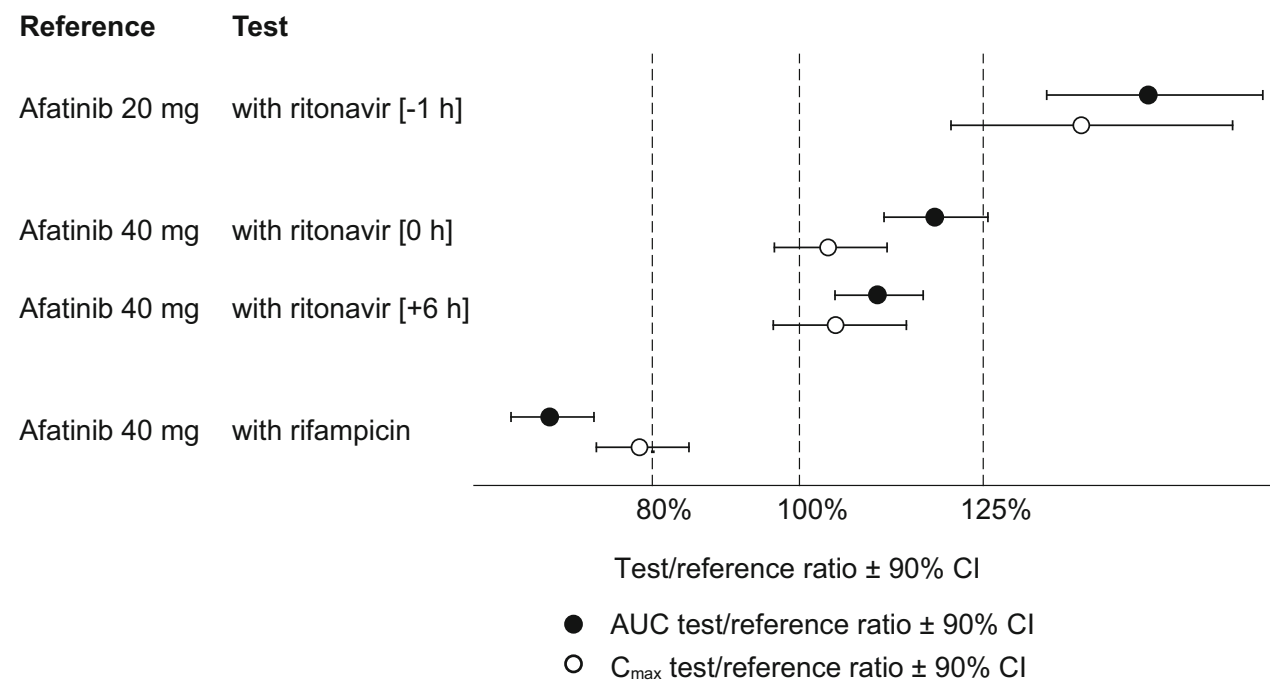

daily) or $12 \mathrm{~h}$ (if administered once daily) from afatinib dosing [18]. Furthermore, the afatinib daily dose can be reduced by $10 \mathrm{mg}$ if not tolerated, and increased to the previous dose level, if concomitant treatment with P-gp inhibitors is stopped [17].

As exposure to ritonavir was sufficient to inhibit BCRP in the two studies [46], it is assumed that a possible interaction with BCRP inhibitors is also covered by the drug-drug interaction studies with ritonavir. Thus, it can be concluded that afatinib exposure is mildly, if at all, increased by BCRP inhibition.

\subsection{Rifampicin}

In healthy subjects [45], pretreatment with the potent P-gp inducer rifampicin (600 $\mathrm{mg}$ once daily) for 7 days decreased plasma exposure of afatinib $40 \mathrm{mg}$ by $34 \%$ $\left(\mathrm{AUC}_{\infty}\right)$ and $22 \%\left(C_{\max }\right)$ (Fig. 4). Therefore, coadministration with $\mathrm{P}-\mathrm{gp}$ inducers should be avoided as this may result in decreased exposure to afatinib. However, if patients require chronic treatment with a $\mathrm{P}$-gp inducer, the afatinib daily dose can be increased by $10 \mathrm{mg}$ as tolerated, and then lowered to the previous dose 2-3 days after the $\mathrm{P}-\mathrm{gp}$ inducer is discontinued [17].

\subsection{Anticancer Therapy}

The pharmacokinetics of afatinib have been studied in combination with standard chemotherapy agents, including letrozole [47], paclitaxel [48], pemetrexed [49], docetaxel [50], vinorelbine [51], temozolomide [52], trastuzumab [53, 54], nintedanib [55], carboplatin [56], paclitaxel/bevacizumab [56], cisplatin/paclitaxel [56, 57] and cisplatin/ 5-fluorouracil [57]. In most of these studies, the primary objective was to determine the maximum tolerated dose of the combination treatment in patients with advanced solid tumours. None of the studies demonstrated a significant pharmacokinetic interaction between afatinib and the other therapies.

\section{Effect of Other Intrinsic and Extrinsic Factors on Afatinib Pharmacokinetics}

The potential effects of various intrinsic and extrinsic factors were investigated using a population approach. Age, ethnicity, smoking history, alcohol consumption, or the presence of liver metastases had no statistically significant impact on the exposure (AUC) and clearance of afatinib in the respective PopPK analyses [35]. Significant covariates that influenced afatinib exposure included food intake, body weight, sex, Eastern Cooperative Oncology Group (ECOG) performance score, renal function, and the level of several serum variables (alkaline phosphatase, lactate dehydrogenase [LDH] or total protein). Female patients had a $15 \%$ increase in exposure when accounting for all other covariate effects (particularly weight), while exposure was increased by $26 \%$ for a $42 \mathrm{~kg}$ patient $(2.5 \mathrm{th}$ percentile) relative to a patient weighing $62 \mathrm{~kg}$ (median within the analysed population). Other than a $\mathrm{CL}_{\mathrm{CR}}$ of $30 \mathrm{~mL} / \mathrm{min}$, these covariates had little influence on afatinib exposure (Fig. 3), with only the upper $95 \%$ CI of AUC for body weight $42 \mathrm{~kg}$ ( 2.5 th percentile), ECOG score $>2$ or higher, alkaline phosphatase 509 U/L (97.5th percentile), LDH 893 U/L (97.5th percentile) exceeding $125 \%$. Varying those covariates within the observed extreme values (2.5th or 97.5th percentile of the baseline values) increased exposure by $27.8 \%$ for $\mathrm{CL}_{\mathrm{CR}} 43 \mathrm{~mL} / \mathrm{min}$ (2.5th percentile), or decreased exposure by $26 \%$ for food intake less than $3 \mathrm{~h}$ before or less than $1 \mathrm{~h}$ after afatinib 
administration. In simulations of the individual covariate effects, all of the individual covariate effects were within the $90 \%$ prediction interval plasma concentration-time profile for a typical patient (electronic supplementary Fig. 2).

As mentioned above, smoking history had no significant effect on plasma exposure of afatinib in the PopPK analysis [35]. This was expected based on the minor metabolism of afatinib, in which CYP enzymes such as CYP1A1/1A2, which are induced by smoking [58], play a negligible role.

\section{Clinical Pharmacodynamics}

\subsection{Effect on Cardiac Repolarisation}

The effect of afatinib $50 \mathrm{mg}$ on cardiac repolarisation was studied in 60 patients with advanced solid tumours. The mean time-matched QT interval using the Fridericia correction method (QTcF) over 1-24 h following administration of afatinib, showed a non-significant decrease of $0.3 \mathrm{~ms}$ ( $90 \% \mathrm{CI}-2.8$ to $2.3 \mathrm{~ms}$ ) between baseline and day 14. No changes in the mean QTc interval $>20 \mathrm{~ms}$ were detected and no patient had new-onset prolongation of the QTcF interval ( $>450 \mathrm{~ms}$ ) or an uncorrected QT interval of $>500 \mathrm{~ms}$ on days 1 or 14 [33]. No correlation was observed between pharmacokinetic parameters and electrocardiogram (ECG) variables, and no treatment-related morphological ECG abnormalities were detected. Thus, the data indicate that afatinib does not affect the QTc interval and therefore no specific ECG monitoring is indicated clinically.

\subsection{Exposure-Response Relationships}

The association between afatinib trough plasma concentrations and efficacy endpoints was investigated in the LUX-Lung 3 trial [19] (Boehringer Ingelheim, unpublished data) [26]. For this analysis, afatinib trough plasma concentrations on the last day of sampling (day 42) were taken (or days 29 or 21 if missing). The relationship between trough afatinib concentrations, categorised using the quartile values, was explored according to week 6 tumour shrinkage, measured as the absolute and percentage change in the sum of target lesion diameters from randomisation (Table 6). No correlation between afatinib trough plasma concentrations and any tumour shrinkage could be detected.

The association between afatinib trough plasma concentrations and severity of the adverse events (AEs) diarrhoea and rash/acne was investigated using pooled data from several trials [19, 59-62] (Boehringer Ingelheim, unpublished data) [26]. For this analysis, the severity of diarrhoea and skin rash/acne during treatment, as measured by the maximum grades for these AEs (graded according to the National Cancer Institute Common Terminology Criteria for Adverse Events [CTCAE] Version 3.0), were compared against afatinib trough plasma concentrations on day 15 (the first day of pharmacokinetic sampling), as the onset of these AEs generally occurs within the first or second week of afatinib treatment. The median trough plasma concentration of afatinib was calculated among patients per maximum CTCAE grade observed (Table 7). Median afatinib trough plasma concentrations were increased with the severity of diarrhoea and rash/acne, suggesting that higher exposure of afatinib increases the risk of experiencing CTCAE grade 3 or higher toxicity or grade 2 or higher diarrhoea events.

Afatinib-related AEs are generally managed with dose modifications; in the case of grade 3 or selected, prolonged grade $2 \mathrm{AE}$ events, the dose can be reduced by $10 \mathrm{mg}$ decrements to $30 \mathrm{mg}$ or a final dose of $20 \mathrm{mg}$ [17, 18]. A dose modification schedule based on tolerability was applied in the LUX-Lung 3 trial [19]. Patients started with a dose of afatinib $40 \mathrm{mg}$, but should be dose-escalated to $50 \mathrm{mg}$ in case of good tolerability, and dose reduced to $30 \mathrm{mg}$ and $20 \mathrm{mg}$ in case afatinib was not tolerated. Post hoc analyses from LUX-Lung 3 assessed the influence of afatinib dose reduction on trough concentrations [63] (Fig. 5). By applying this dose modification schedule,

Table 6 Relationship between tumour shrinkage and quartiles of afatinib trough plasma concentrations in the LUX-Lung 3 trial [19] (Boehringer Ingelheim, unpublished data) [26]

\begin{tabular}{lllll}
\hline Parameter and unit & \multicolumn{4}{l}{ Quartiles of afatinib trough plasma concentrations $(n=193)$} \\
\cline { 2 - 5 } & Trough $\leq \mathrm{Q} 1$ & $\mathrm{Q} 1<$ trough $\leq$ median & Median $<$ trough $\leq \mathrm{Q} 3$ & Trough $>\mathrm{Q} 3$ \\
\hline Decrease from baseline to week 6 in sum of target lesion diameters & & & \\
Patients with trough/tumour measurements, $n(\%)$ & $49(100.0)$ & $48(100.0)$ & $48(100.0)$ & -12.80 \\
Maximum decrease from baseline, $\mathrm{mm}^{\mathrm{b}}$ & -13.00 & -8.40 & -30.45 & -14.65 \\
Maximum \% mm decrease from baseline & -30.27 & -22.66 & -25.15 \\
\hline
\end{tabular}

${ }^{a}$ Based on independent review

b Data are expressed as median values 
Table 7 Relationship between maximum CTCAE grades of diarrhoea and rash and afatinib trough plasma concentrations for patients with evaluable pharmacokinetic data across the dose range 40-50 mg in the LUX-Lung 1-4 trials [19, 59-62] (Boehringer Ingelheim, unpublished data) [26]

\begin{tabular}{|c|c|c|c|c|c|c|}
\hline \multirow[t]{3}{*}{ CTCAE grade } & \multicolumn{6}{|c|}{ Afatinib trough plasma concentrations $(\mathrm{ng} / \mathrm{mL})$ on day 15} \\
\hline & \multicolumn{2}{|c|}{$50 \mathrm{mg}$ starting dose $\mathrm{e}^{\mathrm{a}}$} & \multicolumn{2}{|c|}{$40 \mathrm{mg}$ starting dose $\mathrm{e}^{\mathrm{b}}$} & \multicolumn{2}{|c|}{ Total $^{\mathrm{c}}$} \\
\hline & $N$ & Median & $N$ & Median & $N$ & Median \\
\hline \multicolumn{7}{|l|}{ Diarrhoea } \\
\hline 0 (none) & & & 1 & 86.4 & 1 & 86.4 \\
\hline 1 & 159 & 35.6 & 113 & 25.2 & 272 & 31.3 \\
\hline 2 & 152 & 44.1 & 93 & 31.6 & 245 & 39.6 \\
\hline 3 & 90 & 50.1 & 35 & 35.8 & 125 & 47.5 \\
\hline \multicolumn{7}{|l|}{ Rash/acne } \\
\hline 1 & 125 & 37.9 & 77 & 27.6 & 202 & 34.4 \\
\hline 2 & 164 & 39.9 & 111 & 26.8 & 275 & 34.2 \\
\hline 3 & 73 & 52.1 & 39 & 31.4 & 112 & 45.1 \\
\hline
\end{tabular}

CTCAE National Cancer Institute Common Terminology Criteria for Adverse Events Version 3.0, NSCLC non-small cell lung cancer, TKI tyrosine kinase inhibitor

a TKI-naïve patients in LUX-Lung 2 [59] and LUX-Lung 3 [19] who received an afatinib starting dose of $40 \mathrm{mg}$

b TKI-resistant NSCLC patients in LUX-Lung 1 [60] and LUX-Lung 4 [61, 62] who received an afatinib starting dose of $50 \mathrm{mg}$

c Both NSCLC patient populations (i.e. 40 and $50 \mathrm{mg}$ starting doses in LUX-Lung 1-4) [19, 59-62]

Fig. 5 Comparison of afatinib trough plasma concentrations on days 22 and 43 in patients who remained on afatinib $40 \mathrm{mg}$, reduced their dose to $30 \mathrm{mg}$, or escalated to $50 \mathrm{mg}$ in the LUXLung 3 trial [19, 63]. Striped boxes indicate patients who remained on $40 \mathrm{mg}$ until day 43 (cycle 3 , visit $1, n=126$ ). Grey boxes indicate patients who reduced their dose to $30 \mathrm{mg}$ before day 43 ( $n=38$; only 10 of these patients had valid trough concentrations on afatinib $40 \mathrm{mg}$ at day 22 [cycle 2 , visit 1 ; the rest had either no pharmacokinetic sampling due to dose interruption, were already receiving afatinib $30 \mathrm{mg}$, or were excluded due to invalid sampling]). White boxes indicate patients who dose escalated to $50 \mathrm{mg}$ before cycle 3 , visit $1(n=14)$

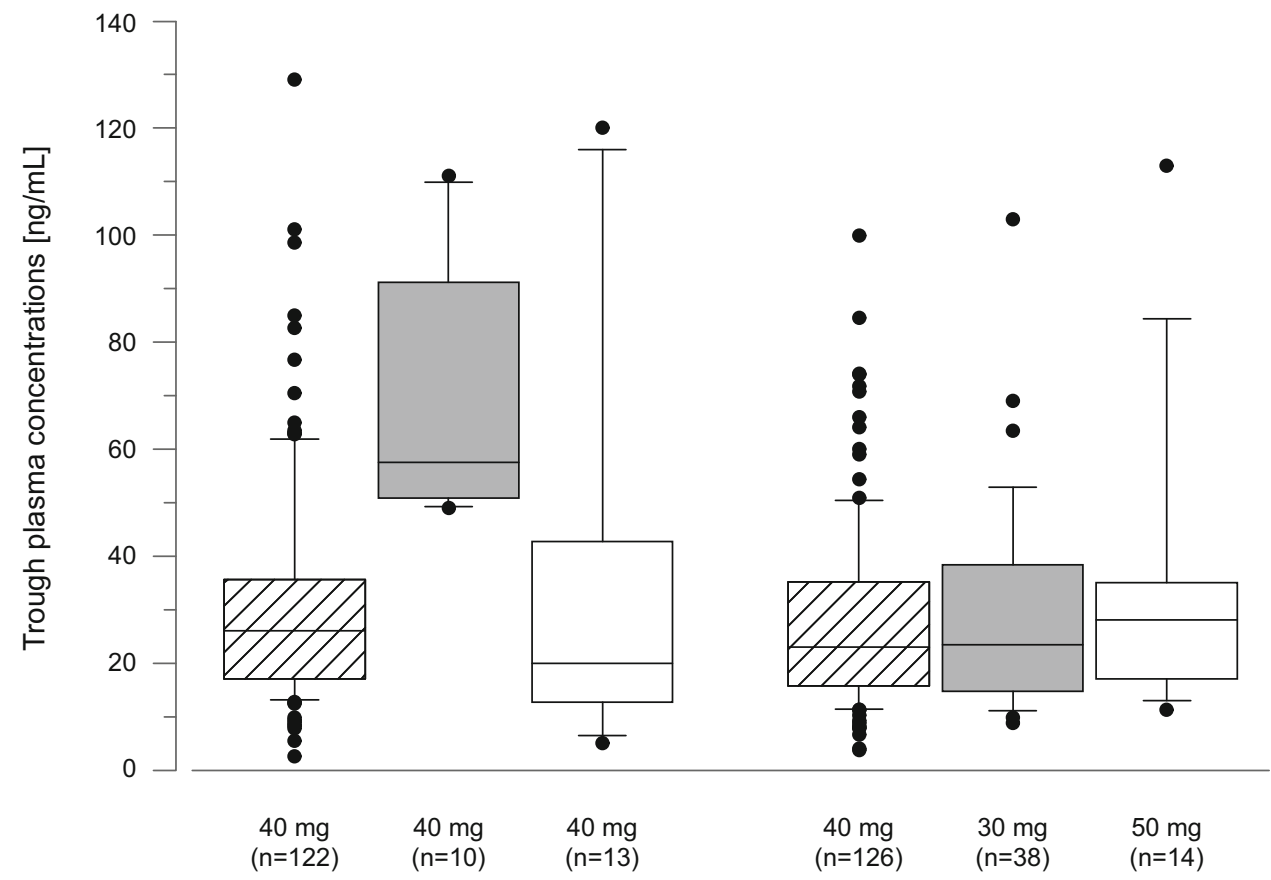

Day 22 (cycle 2, visit 1) $(n=165)$
Day 43 (cycle 3, visit 1)
Individual data with median and 25 th/75th percentiles
T 10th/90th percentiles

- Datapoints outside percentiles 
variability in trough plasma concentration was decreased from day 22 to day 43, as, in general, patients with higher plasma exposure were dose reduced to $30 \mathrm{mg}$ and, in patients with lower plasma exposure, the dose was escalated to afatinib $50 \mathrm{mg}$. At the time of the last pharmacokinetic observation on day 43, gMean trough plasma concentrations were in the same range for all patients, independent of the afatinib dose, indicating that the dose modification schedule was effective in reducing the variability and bringing the patients to a tolerated plasma exposure.

\section{Summary/Conclusions}

In patients with solid tumours, peak plasma concentrations of afatinib occur approximately $2-5 \mathrm{~h}$ after oral dosing and decline afterwards in an at least bi-exponential manner. Afatinib metabolism is minimal, with unchanged drug predominantly excreted in the faeces and approximately $5 \%$ in urine. The effective half-life is approximately $37 \mathrm{~h}$, justifying a once-daily dosing regimen. Over the clinical dose range $20-50 \mathrm{mg}$, the pharmacokinetics of afatinib are slightly more than dose proportional. The main covariates for afatinib exposure are body weight and renal function, while factors such as age, ethnicity, smoking status or hepatic function have no relevant influence. Predicted exposure increases for female patients, patients with low body weight or patients with impaired renal function are within the variability range of afatinib exposure.

At the approved afatinib dose of $40 \mathrm{mg}$, there is low drug-drug interaction potential. Afatinib pharmacokinetics are not affected by commonly coprescribed medications such as CYP inducers/inhibitors and acid-reducing agents, but concomitant treatment with strong inhibitors or inducers of P-gp can affect the pharmacokinetics of afatinib, and thus caution is advisable with this combination. At a dose of $50 \mathrm{mg}$, afatinib does not have proarrhythmic potential.

In conclusion, the studies discussed in this review support the use of afatinib as an efficacious and well-tolerated treatment for patients in its approved indications. In routine clinical practice, afatinib may offer a number of theoretical advantages compared with first-generation TKIs, notably the lack of CYP-related interaction potential, thereby decreasing the risk of drug-drug interactions [64].

Acknowledgments The authors would like to thank Marion Schmid for technical support.

\section{Compliance with Ethical Standards}

Conflicts of interest Sven Wind, David Schnell, Thomas Ebner, Matthias Freiwald and Peter Stopfer are full-time employees of Boehringer Ingelheim.

Ethical approval All procedures performed in studies involving human participants were in accordance with the ethical standards of the independent ethics committee and with the 1964 Helsinki declaration and its later amendments or comparable ethical standards.

Informed consent Informed consent was obtained from all individual human participants included in the described studies.

Open Access This article is distributed under the terms of the Creative Commons Attribution-NonCommercial 4.0 International License (http://creativecommons.org/licenses/by-nc/4.0/), which permits any noncommercial use, distribution, and reproduction in any medium, provided you give appropriate credit to the original author(s) and the source, provide a link to the Creative Commons license, and indicate if changes were made.

\section{References}

1. Arteaga CL. Epidermal growth factor receptor dependence in human tumors: more than just expression? Oncologist. 2002; 7(Suppl 4):31-9.

2. Ciardiello F, Tortora G. EGFR antagonists in cancer treatment. N Engl J Med. 2008;358:1160-74.

3. Sharma SV, Bell DW, Settleman J, et al. Epidermal growth factor receptor mutations in lung cancer. Nat Rev Cancer. 2007;7:169-81.

4. Mok TS, Wu YL, Thongprasert S, et al. Gefitinib or carboplatinpaclitaxel in pulmonary adenocarcinoma. $N$ Engl $J$ Med. 2009;361:947-57.

5. Mitsudomi T, Morita S, Yatabe Y, et al. Gefitinib versus cisplatin plus docetaxel in patients with non-small-cell lung cancer harbouring mutations of the epidermal growth factor receptor (WJTOG3405): an open label, randomised phase 3 trial. Lancet Oncol. 2010;11:121-8.

6. Maemondo $\mathrm{M}$, Inoue $\mathrm{A}$, Kobayashi $\mathrm{K}$, et al. Gefitinib or chemotherapy for non-small-cell lung cancer with mutated EGFR. N Engl J Med. 2010;362:2380-8.

7. Zhou C, Wu YL, Chen G, et al. Erlotinib versus chemotherapy as first-line treatment for patients with advanced EGFR mutationpositive non-small-cell lung cancer (OPTIMAL, CTONG-0802): a multicentre, open-label, randomised, phase 3 study. Lancet Oncol. 2011;12:735-42.

8. Rosell R, Carcereny E, Gervais R, et al. Erlotinib versus standard chemotherapy as first-line treatment for European patients with advanced EGFR mutation-positive non-small-cell lung cancer (EURTAC): a multicentre, open-label, randomised phase 3 trial. Lancet Oncol. 2012;13:239-46.

9. Sequist LV, Waltman BA, Dias-Santagata D, et al. Genotypic and histological evolution of lung cancers acquiring resistance to EGFR inhibitors. Sci Transl Med. 2011;3:7526.

10. Yu HA, Arcila ME, Rekhtman N, et al. Analysis of tumor specimens at the time of acquired resistance to EGFR-TKI therapy in 155 patients with EGFR-mutant lung cancers. Clin Cancer Res. 2013;19:2240-7.

11. Kosaka T, Yatabe Y, Endoh H, et al. Analysis of epidermal growth factor receptor gene mutation in patients with non-small cell lung cancer and acquired resistance to gefitinib. Clin Cancer Res. 2006;12:5764-9. 
12. Yun CH, Mengwasser KE, Toms AV, et al. The T790M mutation in EGFR kinase causes drug resistance by increasing the affinity for ATP. Proc Natl Acad Sci USA. 2008;105:2070-5.

13. Wu SG, Liu YN, Tsai MF, et al. The mechanism of acquired resistance to irreversible EGFR tyrosine kinase inhibitor-afatinib in lung adenocarcinoma patients. Oncotarget. 2016;7: 12404-13.

14. Reid A, Vidal L, Shaw H, et al. Dual inhibition of ErbB1 (EGFR/ HER1) and ErbB2 (HER2/neu). Eur J Cancer. 2007;43:481-9.

15. Li D, Ambrogio L, Shimamura T, et al. BIBW2992, an irreversible EGFR/HER2 inhibitor highly effective in preclinical lung cancer models. Oncogene. 2008;27:4702-11.

16. Solca F, Dahl G, Zoephel A, et al. Target binding properties and cellular activity of afatinib (BIBW 2992), an irreversible ErbB family blocker. J Pharmacol Exp Ther. 2012;343:342-50.

17. Boehringer Ingelheim. Gilotrif [prescribing information] (2016) Boehringer Ingelheim Pharmaceuticals, Inc., Ridgefield, CT. http://www.gilotrif.com/. Accessed 7 Jun 2016.

18. European Medicines Agency. Giotrif: summary of product characteristics, version 24 May 2016. http://www.ema.europa.eu/ docs/en_GB/document_library/EPAR_-_Product_Information/ human/002280/WC500152392.pdf. Accessed 7Jun 2016.

19. Sequist LV, Yang JC, Yamamoto N, et al. Phase III study of afatinib or cisplatin plus pemetrexed in patients with metastatic lung adenocarcinoma with EGFR mutations. J Clin Oncol. 2013;31:3327-34.

20. Wu YL, Zhou C, Hu CP, et al. Afatinib versus cisplatin plus gemcitabine for first-line treatment of Asian patients with advanced non-small-cell lung cancer harbouring EGFR mutations (LUX-Lung 6): an open-label, randomised phase 3 trial. Lancet Oncol. 2014;15:213-22.

21. Yang JC, Wu YL, Schuler M, et al. Afatinib versus cisplatinbased chemotherapy for EGFR mutation-positive lung adenocarcinoma (LUX-Lung 3 and LUX-Lung 6): analysis of overall survival data from two randomised, phase 3 trials. Lancet Oncol. 2015;16:141-51.

22. Soria JC, Felip E, Cobo M, et al. Afatinib versus erlotinib as second-line treatment of patients with advanced squamous cell carcinoma of the lung (LUX-Lung 8): an open-label randomised controlled phase 3 trial. Lancet Oncol. 2015;16:897-907.

23. European Medicines Agency. Giotrif. Procedural steps taken and scientific information after the authorisation. 2016. http://www. ema.europa.eu/docs/en_GB/document_library/EPAR_-_Procedural_ steps_taken_and_scientific_information_after_authorisation/ human/002280/WC500177054.pdf. Accessed 19 July 2016.

24. Modjtahedi H, Cho BC, Michel MC, et al. A comprehensive review of the preclinical efficacy profile of the ErbB family blocker afatinib in cancer. Naunyn Schmiedebergs Arch Pharmacol. 2014;387:505-21.

25. European Medicines Agency. Committee for Medicinal Products for Human Use (CHMP) Assessment report for Giotrif (afatinib). 2013. http://www.ema.europa.eu/docs/en_GB/document_library/ EPAR_-_Public_assessment_report/human/002280/WC5001523 94.pdf. Accessed 17 Mar 2016.

26. FDA Center for Drug Evaluation and Research. Afatinib clinical pharmacology NDA review. 2013. http://www.accessdata.fda. gov/drugsatfda_docs/nda/2013/201292Orig1s000ClinPharmR. pdfAccessed 17 Mar 2016.

27. FDA Center for Drug Evaluation and Research (CDER). Guidance for industry. Drug interaction studies: study design, data analysis, implications for dosing, and labeling recommendations. US FDA draft guidance. 2012. http://www.fda.gov/downloads/ Drugs/GuidanceComplianceRegulatoryInformation/Guidances/ ucm292362.pdf. Accessed 17 Mar 2016.

28. FDA Center for Drug Evaluation and Research. Afatinib pharmacology NDA\# 201292 review. 2013. http://www.accessdata.
fda.gov/drugsatfda_docs/nda/2013/201292Orig1s000PharmR. pdf. Accessed 17 Mar 2016.

29. Eskens FA, Mom CH, Planting AS, et al. A phase I dose escalation study of BIBW 2992, an irreversible dual inhibitor of epidermal growth factor receptor 1 (EGFR) and 2 (HER2) tyrosine kinase in a 2-week on, 2-week off schedule in patients with advanced solid tumours. Br J Cancer. 2008;98:80-5.

30. Yap TA, Vidal L, Adam J, et al. Phase I trial of the irreversible EGFR and HER2 kinase inhibitor BIBW 2992 in patients with advanced solid tumors. J Clin Oncol. 2010;28:3965-72.

31. Marshall J, Hwang J, Eskens FA, et al. A Phase I, open-label, dose escalation study of afatinib, in a 3-week-on/1-week-off schedule in patients with advanced solid tumors. Invest New Drugs. 2013;31:399-408.

32. Gordon MS, Mendelson DS, Gross M, et al. A Phase I, openlabel, dose-escalation study of continuous once-daily oral treatment with afatinib in patients with advanced solid tumors. Invest New Drugs. 2013;31:409-16.

33. Molife LR, Rudman SM, Alam S, et al. Phase II, open-label trial to assess QTcF effects, pharmacokinetics and antitumor activity of afatinib in patients with relapsed or refractory solid tumors. Cancer Chemother Pharmacol. 2013;72:1213-22.

34. Wind S, Schmid M, Erhardt J, et al. Pharmacokinetics of afatinib, a selective irreversible ErbB family blocker, in patients with advanced solid tumours. Clin Pharmacokinet. 2013;52:1101-9.

35. Freiwald M, Schmid U, Fleury A, et al. Population pharmacokinetics of afatinib, an irreversible ErbB family blocker, in patients with various solid tumors. Cancer Chemother Pharmacol. 2014;73:759-70.

36. Boehringer Ingelheim. Relative bioavailability of a single dose of $20 \mathrm{mg}$ BIBW 2992 administered as tablet (final formulation) compared to BIBW 2992 drinking solution and BIBW 2992 tablet (trial formulation II) following oral administration to healthy male volunteers (an open-label, randomised, single-dose, threeway crossover phase I study). Trial No. 1200.35. http://trials. boehringer-ingelheim.com/content/dam/internet/opu/clinicaltrial/ com_EN/results/1200/1200.35_U09-2233-02.pdf. Accessed 17 Mar 2016.

37. FDA Center for Drug Evaluation and Research (CDER). Guidance for industry. Food-effect bioavailability and fed bioequivalence studies. US FDA draft guidance. 2002. http://www.fda.gov/ downloads/RegulatoryInformation/Guidances/UCM126833.pdf. Accessed 17 Mar 2016.

38. Schnell D, Buschke S, Fuchs H, et al. Pharmacokinetics of afatinib in subjects with mild or moderate hepatic impairment. Cancer Chemother Pharmacol. 2014;74:267-75.

39. Wiebe S, Schnell D, Kulzer R, et al. Influence of renal impairment on the pharmacokinetics of afatinib: an open-label, singlecentre study. Eur J Drug Metab Pharmacokinet. 2016. doi:10. 1007/s13318-016-0359-9.

40. Stopfer P, Marzin K, Narjes H, et al. Afatinib pharmacokinetics and metabolism after oral administration to healthy male volunteers. Cancer Chemother Pharmacol. 2012;69:1051-61.

41. US FDA Center for Drug Evaluation and Research. US Department of Health and Human Services, Food and Drug Administration, Center for Drug Evaluation and Research (CDER). Guidance for industry. Pharmacokinetics in patients with impaired renal function: study design, data analysis, and impact on dosing and labeling. 2010. http://www.fda.gov/downloads/ Drugs/GuidanceComplianceRegulatoryInformation/Guidances/ UCM204959.pdf. Accessed 2 Jan 2016.

42. Nolin TD, Naud J, Leblond FA, et al. Emerging evidence of the impact of kidney disease on drug metabolism and transport. Clin Pharmacol Ther. 2008;83:898-903.

43. Zhang Y, Zhang L, Abraham S, et al. Assessment of the impact of renal impairment on systemic exposure of new molecular entities: 
evaluation of recent new drug applications. Clin Pharmacol Ther. 2009;85:305-11.

44. Moran T, Palmero R, Provencio M, et al. A Phase Ib open label clinical trial of continuous once daily oral afatinib (A) plus sirolimus (S) in patients (Pts) with EGFR mutation positive (EGFR $\mathrm{M}+$ ) NSCLC and/or disease progression following prior erlotinib (E) or gefitinib (G) [abstract no. 1248PA]. Ann Oncol. 2014;25:iv437.

45. Wind S, Giessmann T, Jungnik A, et al. Pharmacokinetic drug interactions of afatinib with rifampicin and ritonavir. Clin Drug Investig. 2014;34:173-82.

46. Tachibana T, Kato M, Watanabe T, et al. Method for predicting the risk of drug-drug interactions involving inhibition of intestinal CYP3A4 and P-glycoprotein. Xenobiotica. 2009;39:430-43.

47. Gunzer K, Joly F, Ferrero JM, et al. A phase II study of afatinib, an irreversible ErbB family blocker, added to letrozole in patients with estrogen receptor-positive hormone-refractory metastatic breast cancer progressing on letrozole. Springerplus. 2016;5:45.

48. Suder A, Ang JE, Kyle F, et al. A phase I study of daily afatinib, an irreversible ErbB family blocker, in combination with weekly paclitaxel in patients with advanced solid tumours. Eur J Cancer. 2015;51:2275-84.

49. Chu QS, Sangha R, Hotte SJ, et al. A phase I, dose-escalation trial of continuous- and pulsed-dose afatinib combined with pemetrexed in patients with advanced solid tumors. Invest New Drugs. 2014;32:1226-35.

50. Awada AH, Dumez H, Hendlisz A, et al. Phase I study of pulsatile 3-day administration of afatinib (BIBW 2992) in combination with docetaxel in advanced solid tumors. Invest New Drugs. 2013;31:734-41.

51. Mukai H, Masuda N, Ishiguro H, et al. Phase I trial of afatinib plus vinorelbine in Japanese patients with advanced solid tumors, including breast cancer. Cancer Chemother Pharmacol. 2015;76:739-50.

52. Reardon DA, Nabors LB, Mason WP, et al. Phase I/randomized phase II study of afatinib, an irreversible ErbB family blocker, with or without protracted temozolomide in adults with recurrent glioblastoma. Neuro Oncol. 2015;17:430-9.

53. Lin NU, Winer EP, Wheatley D, et al. A phase II study of afatinib (BIBW 2992), an irreversible ErbB family blocker, in patients with HER2-positive metastatic breast cancer progressing after trastuzumab. Breast Cancer Res Treat. 2012;133:1057-65.

54. Ring A, Wheatley D, Hatcher $\mathrm{H}$, et al. Phase I study to assess the combination of afatinib with trastuzumab in patients with advanced or metastatic HER2-positive breast cancer. Clin Cancer Res. 2015;21:2737-44.

55. Gordon MS, Springett GM, Su YB, et al. A Phase I dose-escalation study of afatinib combined with nintedanib in patients with advanced solid tumors. Future Oncol. 2015;11:1479-91.

56. Boehringer Ingelheim. A phase I open label trial of continuous dosing with BIBW 2992 combined with paclitaxel and BIBW 2992 combined with paclitaxel and bevacizumab, BIBW 2992 combined with carboplatin and BIBW 2992 combined with paclitaxel and carboplatin in patients with advanced solid tumours. Trial No. 1200.12. http://trials.boehringer-ingelheim. $\mathrm{com} /$ content/dam/internet/opu/clinicaltrial/com_EN/results/1200/ 1200.12_c01802594-02_DR.pdf. Accessed 17 Mar 2016.

57. Vermorken JB, Rottey S, Ehrnrooth E, et al. A phase Ib, openlabel study to assess the safety of continuous oral treatment with afatinib in combination with two chemotherapy regimens: cisplatin plus paclitaxel and cisplatin plus 5-fluorouracil, in patients with advanced solid tumors. Ann Oncol. 2013;24:1392-400.

58. Petros WP, Younis IR, Ford JN, et al. Effects of tobacco smoking and nicotine on cancer treatment. Pharmacotherapy. 2012;32: 920-31.

59. Yang JC, Shih JY, Su WC, et al. Afatinib for patients with lung adenocarcinoma and epidermal growth factor receptor mutations (LUX-Lung 2): a phase 2 trial. Lancet Oncol. 2012;13:539-48.

60. Miller VA, Hirsh V, Cadranel J, et al. Afatinib versus placebo for patients with advanced, metastatic non-small-cell lung cancer after failure of erlotinib, gefitinib, or both, and one or two lines of chemotherapy (LUX-Lung 1): a phase $2 \mathrm{~b} / 3$ randomised trial. Lancet Oncol. 2012;13:528-38.

61. Murakami H, Tamura T, Takahashi T, et al. Phase I study of continuous afatinib (BIBW 2992) in patients with advanced nonsmall cell lung cancer after prior chemotherapy/erlotinib/gefitinib (LUX-Lung 4). Cancer Chemother Pharmacol. 2012;69:891-9.

62. Katakami N, Atagi S, Goto K, et al. LUX-Lung 4: a phase II trial of afatinib in patients with advanced non-small-cell lung cancer who progressed during prior treatment with erlotinib, gefitinib, or both. J Clin Oncol. 2013;31:3335-41.

63. Yang JC, Ahn MJ, Dickgreber NJ, et al. Influence of dose adjustment on afatinib safety and efficacy in patients (pts) with advanced EGFR mutation-positive (EGFRm+) non-small cell lung cancer (NSCLC). J Clin Oncol. 2015;33(15_Suppl):8073.

64. Song X, Varker H, Eichelbaum M, et al. Treatment of lung cancer patients and concomitant use of drugs interacting with cytochrome P450 isoenzymes. Lung Cancer. 2011;74:103-11. 